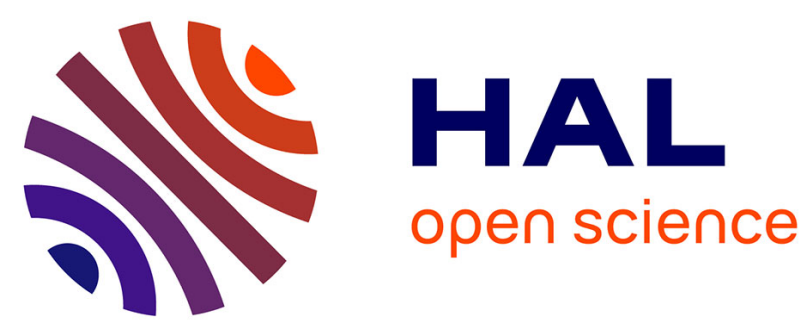

\title{
Model of Monetarisation of the Non-availability of Intralogistics Systems for the Evaluation of System Design Alternatives
}

Friederike Rechl, Konstantin Krebs, Willibald A. Günthner

\section{To cite this version:}

Friederike Rechl, Konstantin Krebs, Willibald A. Günthner. Model of Monetarisation of the Nonavailability of Intralogistics Systems for the Evaluation of System Design Alternatives. 13th IFIP International Conference on Product Lifecycle Management (PLM), Jul 2016, Columbia, SC, United States. pp.523-536, 10.1007/978-3-319-54660-5_47 . hal-01699669

\section{HAL Id: hal-01699669 \\ https://hal.inria.fr/hal-01699669}

Submitted on 2 Feb 2018

HAL is a multi-disciplinary open access archive for the deposit and dissemination of scientific research documents, whether they are published or not. The documents may come from teaching and research institutions in France or abroad, or from public or private research centers.
L'archive ouverte pluridisciplinaire HAL, est destinée au dépôt et à la diffusion de documents scientifiques de niveau recherche, publiés ou non, émanant des établissements d'enseignement et de recherche français ou étrangers, des laboratoires publics ou privés.

\section{(c)(1)}

Distributed under a Creative Commons Attribution| 4.0 International License 


\title{
Model of Monetarisation of the Non-Availability of Intralogistics Systems for the Evaluation of System Design Alternatives
}

\author{
Friederike Rechl $^{1^{*}}$, Konstantin Krebs², Willibald A. Günthner ${ }^{3}$ \\ ${ }^{1} \mathrm{fml}$ - Institute for Materials Handling, Material Flow, Logistics, Technical University of \\ Munich, Garching, Germany \\ rechl@fml.mw.tum.de \\ ${ }^{2} \mathrm{fml}$ - Institute for Materials Handling, Material Flow, Logistics, Technical University of \\ Munich, Garching, Germany \\ konstantinkrebs@googlemail.com \\ ${ }^{3} \mathrm{fml}$ - Institute for Materials Handling, Material Flow, Logistics, Technical University of \\ Munich, Garching, Germany \\ kontakt@fml.mw.tum.de
}

\begin{abstract}
Intralogistics systems secure the internal flow of materials and are a success factor for handling and producing companies. In general, the objective of analysing life-cycle costs is to economically evaluate system design alternatives aiming at supporting investment decisions. One essential influence factor of operating costs, and thus life-cycle costs, is the availability. The nonavailability significantly influences the operating costs, e.g. repairs or loss of revenues. A research field that has not been investigated in the field of intralogistics is the monetarisation of non-availability. An appropriate cost model is therefore necessary. As a result, the costs of non-availability can be evaluated monetarily as a function of time. With the help of such a monetary parameter, financial risks can already be detected during the planning phase. This paper models an approach of the monetarisation of the non-availability of intralogistics systems as an economical evaluation indicator during the planning phase.
\end{abstract}

Keywords: Intralogistics systems, cost-effectiveness, planning, nonavailability, investment decision.

\section{Motivation and Initial Situation}

Intralogistics systems have become a key competition factor caused by their function of securing the internal flow of material and goods and therefore by increasing cost pressure [1]. Consequently, the requirements concerning availability and costeffectiveness of those systems have grown as well. In the field of plants and machines, several research studies prove that it is less the investment, and more the operating costs, which are responsible for the majority of the total life-cycle costs (LCC) [2]. For that reason, the planning and projection of those systems have become more 
important as the operating costs in particular are significantly influenced by the choice of constructive characteristics and the operational strategy.

A research field, which has not been investigated yet, is the monetarisation of the non-availability (NA) of intralogistics systems. Due to the fact that failures can cause high additional costs in the operating phase (e.g. repairs or loss of revenues), an appropriate calculation model is necessary in order to economically evaluate the NA. With the help of such a model, the NA can be expressed monetarily and financial risks can already be detected in the planning phase.

This paper models an approach for the monetarisation of the NA of intralogistics systems. Consequently, the model can already provide an evaluation parameter for comparing system design alternatives in the planning phase.

\section{Objective and Procedure}

The objective of this paper is the design of a calculation model for the costs of the NA of intralogistics systems as an evaluation parameter of system design alternatives during the planning phase.

Firstly, the term of costs of the NA in the field of intralogistics is defined. Secondly, the current state-of-the-art including approaches for LCC calculation, cost calculation concerning failures and a description of availability concerning operating costs is presented. Thirdly, the system boundary is set concerning the model building with the help of a conveyor and storage technology aspects, as well as a process-based description. Based on that, the monetarisation model and the needed input parameters are presented. Finally, the application of the model is described and the results evaluated with the help of a planning example.

\section{Term Definition of the Costs of Non-Availability}

As regards the NA, several terms in respect of the costs exist. Gudehus [3] introduced the term, shortage costs, which includes loss of profits, contribution margin loss and delivery delay penalties. For the existing approaches in this field, the focus is often set on profit losses. An NA causes the NA of goods if a buffer cannot intercept the goods. Depending on the nature of the company, customers who cannot be supplied, recourse to competitors. This view is especially useful for manufacturing companies. Even a partial loss through reduced revenues or penalties for delay is conceivable.

The shortage costs include so-called opportunity costs (OC), such as lost profits, as described above. In this paper, the objective is set on the costs of NA including OC. Accordingly, the model considers not only the operating costs, which are directly caused by the NA, or are generated during the NA, but also the OC as a consequence. 


\section{State-of-the-Art}

Derived from the definition of availability, the cost of the NA of intralogistics systems can be defined as a monetary measure of the time-dependent, non-functional and therefore unavailable state of a system. [4]

The NA of intralogistics systems can be significantly influenced by the extent of incurred maintenance activities. The extent of NA is visible in the magnitude of repairs, which appear as operating costs. For this reason, the DIN 60300-3-3 recommends considering the availability as costs in economical evaluations. [5]

With regard to the prognosis of maintenance costs, several approaches exist in the field of machines and plants. Compared to the intralogistics, the maintenance costs have been focused and were therefore investigated further. Currently, the topic of maintenance in the field of intralogistics is limited to statutory maintenance measures (e.g. DIN EN 15635) [6].

Other existing models of maintenance cost calculation are mainly of a stochastic nature. Works by Dhillon [7], Fürnrohr [8], Ostwald and McLaren [9] and Fritz [10] can be named. Dhillon presents models for the calculation of preventive and corrective maintenance expenses. The cost models are essentially based on a componentspecific failure rate [7]. In comparison, Fleischer and Wawerla [11] provide a generic approach for estimating the distribution function of a system's repairs based on the mentioned failure rate distribution and on a Monte Carlo simulation to determine the total LCC. In his thesis on stochastic models for forecasting the LCC of complex systems, Fürnrohr shows similar concepts [8]: also based on the concept of a failure rate, Elsayed [12] describes a system reliability estimation for time-independent and default-related models. In contrast to this, Lad and Kulkarni [13] highlight maintenance planning based on the plant structure (e.g. as in regard to equal parts) and present here a model which aims to calculate failure-based follow-up costs.

In practice, the most commonly used approaches are the models provided by the VMDA [14]. Accordingly, the total maintenance and repair costs are tripartite: inspection, planned maintenance, as well as repairs.

The costs of inspection (IH1) are defined as [14]:

$$
I H 1=\sum(I H 1.1 \cdot(I H 1.2 \cdot I H 1.6+I H 1.3+I H 1.4 \cdot I H 1.5)) .
$$

with the frequency per year $I H 1.1$ [number], the required time $I H 1.2$ [h], the material costs $I H 1.3$ [ $€$ ], the average resource time effort $I H 1.4$ [h], the hourly rate of the resource $I H 1.5[€ / \mathrm{h}]$ and the hourly rate of the maintenance personnel $I H 1.6[€ / \mathrm{h}]$.

The cost of the planned maintenance (IH2) (see formula (2)), which is similar to the calculation procedure of IH1, also strongly depends on the frequency per year (IH2.1). Furthermore, the work effort in hours (IH2.2) and the hourly rate of the employee $(I H 2.6)$ are needed. In addition, the resource costs have to be determined with the help of the hourly resource rate ( $I H 2.5)$ and the resource time effort per process (IH2.4). Finally, the material costs (IH2.3) are added. 


$$
I H 2=\sum(I H 2.1 \cdot(I H 2.2 \cdot I H 2.6+I H 2.3+I H 2.4 \cdot I H 2.5)) .
$$

The costs of repair (IH3) are directly determined by the availability [15]:

$$
I H 3=\sum\left(\frac{D 2}{I H 3.1} \cdot(I H 3.2 \cdot I H 3.6+I H 3.3+I H 3.4 \cdot I H 3.5)\right) .
$$

Decisive for the calculation is the mean time between repair operations (IH3.1). This corresponds to the $M T B F$ value (mean time between failures). In addition, the workload per repair process in hours (IH3.2) is required, which is expressed by the value MDT (mean down time). Moreover, the cost of materials (IH3.3), resource costs (IH3.4, IH3.5) and the hourly rate of the maintenance engineer (IH3.6) must be known.

As regards the economic assessment of NA, there are several approaches in the literature. Here, according to the aforementioned concept of Gudehus, the shortage costs are calculated with the help of the ability to deliver products and the shortage costs per product. However, a specific calculation procedure is not described. [3] In a work by Dervisopoulos [15], the consideration of the shortage costs to evaluate the LCC is emphasised, but here, too, a specific calculation procedure is not given.

A concrete calculation method of the shortage costs is presented by Kulkarni und Lad [13] in which the expected total failure costs $E[T C]$ of a component during a defined period is determined by using the expected number of failures $E[N(T)]$ and costs per failure $E[C]$ [13]. According to Höck [16], another calculation model is based on the average output quantity, multiplied by the value in monetary units $W_{\text {piece }}[€ /$ piece].

The short overview on existing models of the costs of NA shows that there are very different approaches when a calculation procedure is not given or the focus is set on follow-up costs. The existing models are not analogous. Furthermore, the mentioned approaches focus on the field of machines and plans. Höck uses, in principle, the capital, which is bound by non-expelled products. Gudehus and Kulkarni use a vague amount of shortage costs per unit for which, however, an explicit calculation rule is also not given; they even propose the use of empirical values or estimations. This underlines the need for a standardised approach to the monetarisation of the costs of NA as a planning parameter in the field of intralogistics.

\section{Definition of the System Boundary}

As regards the model, the focus is set on automated material handling systems. The system boundary includes process-oriented automatic storage and retrieval of handling units (HU) in or from the automatic high-bay warehouse (HBW), or the miniload system (MLS) from or to the transfer point of the automatic conveyor technology. As regards the pack conveyor technology, the personnel costs of the employee are considered in the analysis. The personnel costs of the employee who performs the uptake and release of $\mathrm{HU}$ are taken into account, because the employee works directly 
on the conveyor technology and thus in a stationary workplace. Costs of forklifts, trucks, etc., are not considered.

Process-based, the system boundary can be described as follows. Fig. 1 shows an example of the described technology and interfaces within the system boundary. The introduction of $\mathrm{HU}$ in the system is carried out on the A-point. From there, HU are transported on pallets with pallet conveyor technology in an HBW and stored. The racks are served by one or more stacker cranes (SC) in one or more aisles. The SC are specifically selected for each rack facility. Packs are brought and stored over pack conveyor technology in an MLS. From HBW, HU can be transported via pallet conveyor technology to the E-point and then abandon the system, the same applies for HU from MLS concerning pack conveyor technology. A detailed overview of the described conveyor and storage technology is shown in Fig. 2.

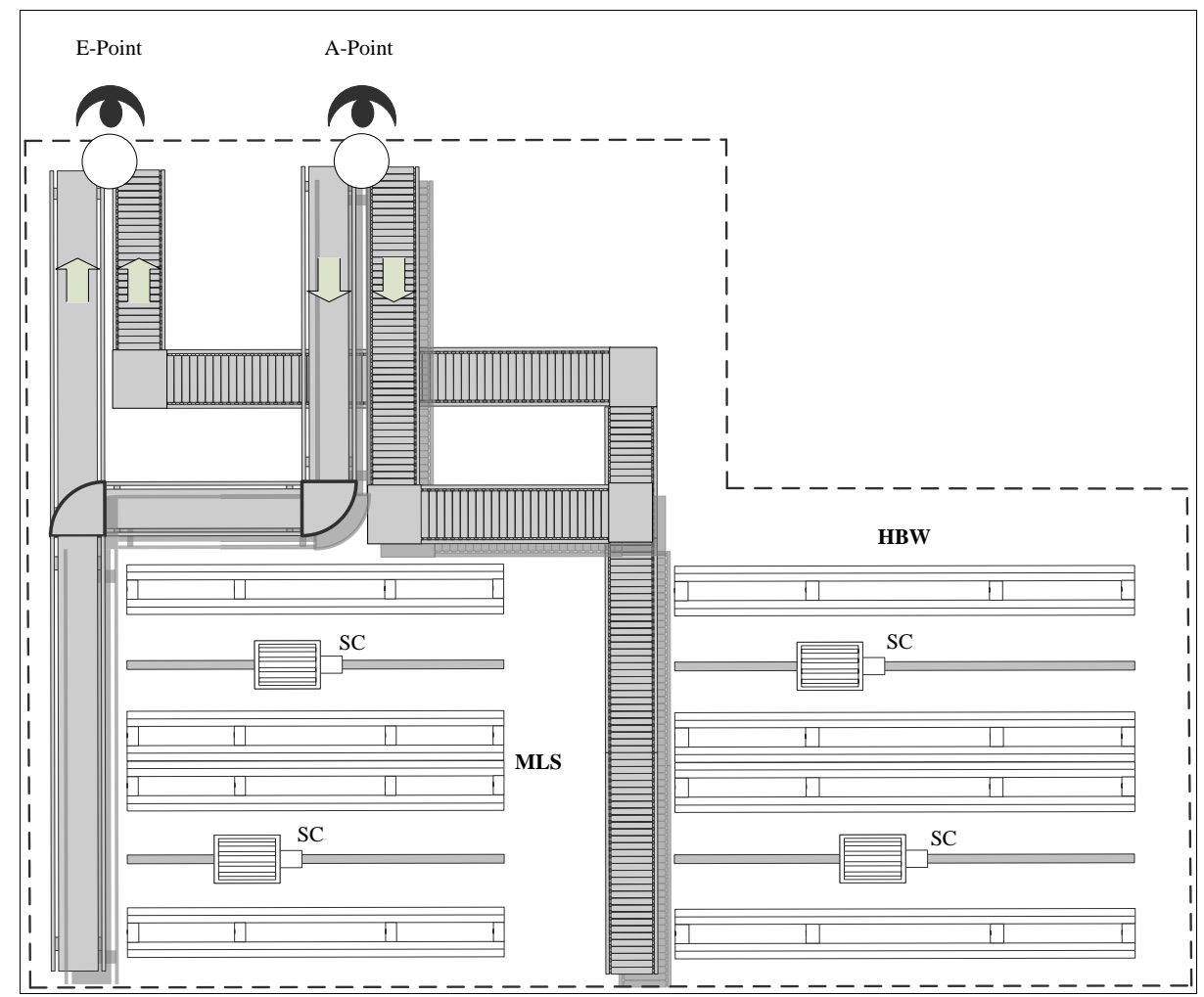

Fig. 1. Schematic representation of an exemplary system boundary including the $A$ and $E$ Point, the high-bay warehouse and the mini-load system with their stacker cranes and the appropriate conveyor technology. A detailed overview of the described conveyor and storage technology is shown in the following figure. 


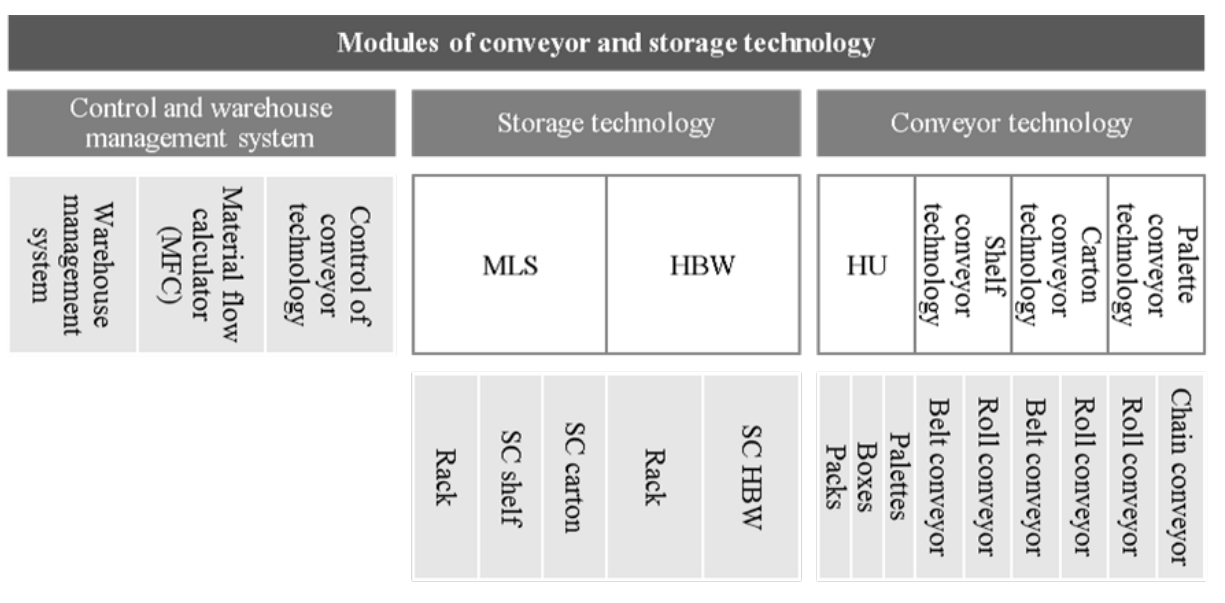

Fig. 2. Exemplary modules of conveyor and storage technology within the system boundary. The grey ones are the modules. The arrangement of modules is used for the generation and understanding of the cost model of non-availability in sections 6 and 7, especially in section 7.2 .

\section{Calculation Model Building of the Costs of Non-Availability}

For the model generation, those LCC are identified first, which are caused by NA or are generated time-based during the NA. In other words, these are the operating costs during the time slice of the NA. Second of all, the OC are added.

As regards the first step, it can be excluded that, during the procurement, implementation and removal phases, costs are generated which are caused by NA. The NA is therefore only relevant during the operating phase of a system, thus only these costs are tested for their NA dependence.

The cost calculation of inspection and planned maintenance are not affected directly by the NA (see section 4, formulas (1) to (3)). High availability may be the result of frequent maintenance and repair works. Nevertheless, it is possible that a system is not available even in the case of regular maintenance and inspections. Furthermore, inspection and planned maintenance have to be executed, even in the case of NA. In addition, the costs of repairs are relevant for the cost model. As regards formulae (1) to (3), only the calculation of repairs includes a variable based directly on the NA, which is the $M T B F$ value. However, as explained, in addition to the costs of repair, the costs of inspection (IH1) and planned maintenance (IH2) must be considered as well.

Besides the maintenance and repair costs, there are further LCC, which are caused by the NA or are generated during an NA. Energy costs are incurred during the operation, as well as in case of NA. During the NA, energy costs can be even lower. Other LCC are the space and surface costs independently incurred by the functionality of the system. Finally, despite the NA, personnel and insurance costs are engendered.

The OC, which are consequential costs due to the NA, are implemented in the model as well. Due to the fact that the OC depend on several factors and aspects, they 
are considered in the model as a variable $C_{\text {opportunity }_{(t)}}$ depending time-based on the NA.

The calculation of the annual cost of NA $C_{N A}$ of intralogistics systems can thus be summarised as follows:

$$
\begin{aligned}
C_{N A_{(t)}=C_{M R}+C_{\text {energy }}+} & C_{\text {surface }}+C_{\text {space }}+C_{\text {personnel }}+C_{\text {insurance }} \\
& +C_{\text {opportunity }} .
\end{aligned}
$$

The maintenance and repair costs $C_{\left.M R_{(} t\right)}$ include the costs of inspection $C_{I(t)(i)}$, planned maintenance $C_{p M(t)(i)}$ and repairs $C_{R(t)(i)}$ :

$$
C_{M R_{(t)}}=C_{I(t)(i)}+C_{p M(t)(i)}+C_{R(t)(i)} .
$$

with (based on formulae (1) to (3))

$$
\begin{gathered}
C_{I(t)(i)}=n_{I(i)} \cdot\left[\left(T_{I(i)} \cdot M A_{I(i)}\right)+C_{M I(i)}+\left(T_{B M I(i)} \cdot B M_{I(i)}\right)\right] . \\
C_{p M(t)(i)}=n_{p M(i)} \cdot\left[\left(T_{p M(i)} \cdot M A_{p M(i)}\right)+C_{M p M(i)}+\left(T_{B M p M(i)} \cdot B M_{p M(i)}\right)\right] . \\
C_{R(t)(i)}=\frac{T_{B}}{M T B F_{(i)}} \cdot\left[\left(M D T_{(i)} \cdot M A_{R(i)}\right)+C_{M R(i)}+\left(T_{B M R(i)} \cdot B M_{R(i)}\right)\right] .
\end{gathered}
$$

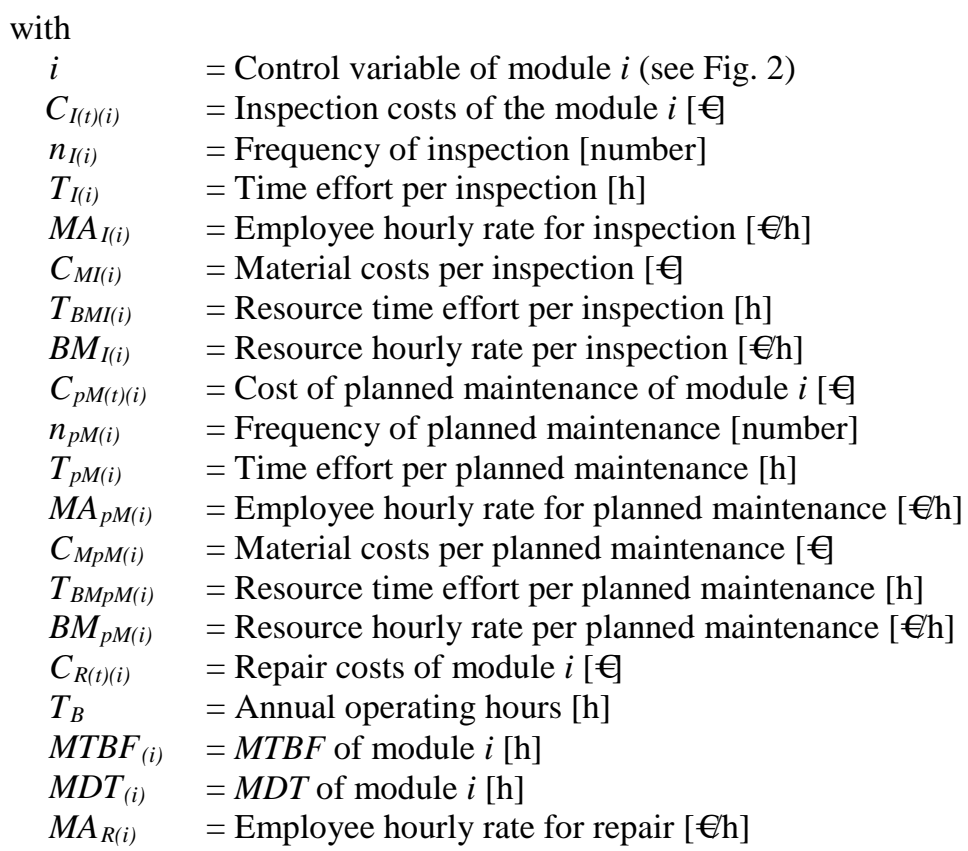


$\begin{array}{ll}C_{M R(i)} & =\text { Material costs per repair }[€] \\ T_{B M R(i)} & =\text { Resource time effort per repair }[\mathrm{h}] \\ B M_{R(i)} & =\text { Resource hourly rate per repair }[€ / \mathrm{h}]\end{array}$

Overall, the formula for calculating the total annual costs $C_{N A}$ of an intralogistics system with $I$ modules is:

$$
\begin{gathered}
C_{N A}=\sum_{i=1}^{I} n_{I(i)} \cdot\left[\left(T_{I(i)} \cdot M A_{I(i)}\right)+C_{M I(i)}+\left(T_{B M I(i)} \cdot B M_{I(i)}\right)\right]+ \\
n_{p M(i)} \cdot\left[\left(T_{p M(i)} \cdot M A_{p M(i)}\right)+C_{M p M(i)}+\left(T_{B M p M(i)} \cdot B M_{p M(i)}\right)\right]+ \\
\frac{T_{B}}{M T B F_{(i)}} \cdot\left[\left(M D T_{(i)} \cdot M A_{R(i)}\right)+C_{M R(i)}+\left(T_{B M R(i)} \cdot B M_{R(i)}\right)\right]+ \\
C_{\text {energy }_{(i)}}+C_{\text {surface }_{(i)}}+C_{\text {space }_{(i)}}+C_{\text {personnel }_{(i)}}+C_{\text {insurance }_{(i)}} \\
+C_{\text {opportunity }_{(i)} .}
\end{gathered}
$$

If the number of inspections per year $\left(n_{I(i)}\right)$ is increased, a higher value of the $M T B F_{(i)}$ value can be expected. The following section demonstrates the application of the calculation model. Furthermore, the model is assessed based on a practical example.

\section{Application of the Model Based on a Practical Example}

The calculation model of the costs of NA of intralogistics systems is demonstrated and evaluated with the help of a practical planning example in this section. For this, the cost and planning data of an intralogistics system of a company from 2009 to 2014 are available. The system comprises a tray warehouse, an MLS and an HBW.

\subsection{Procedure of Data Collection}

As can be seen from the calculation approach in formula (9), data on the maintenance and repairs, energy consumption, surface and space costs, as well as personnel and insurance costs, are required. The OC are considered as a variable. The cost data in respect of the insurance, the personnel, the surface and space can be taken out of the planning and implementation documents. Energy costs were modelled based on the description of the used conveyor and storage technology components with their technical information, as well as on two research works $[17,18]$. The maintenance and repair cost data are accessible in the firm's $\mathrm{ERP}^{1}$ system.

\footnotetext{
${ }^{1}$ Enterprise resource planning.
} 


\subsection{Analysis of Data and Determination of Module Cost Data}

First of all, the used storage and conveyor technology based on the raw data are categorised. They are divided into so-called modules, being equal to the scheme of conveyor and storage in Fig. 2. Overall, there are thus nine modules:

- $\quad$ Pallet conveyor technology (chain and roll)

- $\quad$ Carton conveyor technology (roll and belt)

- $\quad$ Shelf conveyor technology (roll and belt)

- $\quad$ HBW SC

- $\quad$ MLS carton SC

- $\quad$ MLS shelf SC

As regards the presented cost model in formula (9), the generation of cost data is as follows. The costs of inspection, planned maintenance and repair are charged as a flat rate, since no dedicated data on hourly rates, resource costs and material costs are known. Furthermore, a differentiation between the costs of inspection and planned maintenance cannot be made. The cost shares for each module (e.g. palette conveyor technology chain) are considered proportionally. The weighting is determined by the ratio of the total number of executed activities to the total number of the module group (e.g. palette conveyor technology).

As regards the calculation of energy costs, it should be noted that the energy consumption needs to be specified both under load, and in standby mode. The total energy consumption of the conveyor technology in standby is specified per metre. Knowing the length of the module means that the standby energy consumption per year can be calculated. The energy costs are then calculated by multiplying the energy consumption with the energy price.

Since the annual administrative overheads (AO) are only known for the entire system, they must be divided between the conveyor technology and racks, including the SC. For this purpose, the ratio of the investment costs of the conveyor technology and racks in respect to SC are determined and the AO are divided accordingly. The proportion of AO is then spread over the surface of the modules in order to obtain the surface cost rate. To calculate the surface costs, the surface of each module has to be determined. The width of modules is known and is multiplied by the length. In the case of SC, the length corresponds to the length of the rack aisle.

The annual personnel costs are calculated based on the time slice of NA $\left(M D T_{(i)}\right)$, the number of employees and the employee hourly rate:

$$
C_{\text {personnel }_{(i)}}=\sum_{i=1}^{I} M D T_{i} \cdot \text { number of employees } \cdot \text { hourly rate } .
$$

The insurance costs are determined in a similar way to the AO. Higher investment costs require higher insurance rates, so the approach is justified. The insurance costs of SC components can thus be directly specified. For the conveyor modules, the insurance costs are standardised to metres and then multiplied by the length.

Based on the aggregation of the data, cost data sheets can be provided for each module. Hence, these data sheets include the input data for the calculation model of the costs of NA (see formula (9)). 
In the case of planning, the idea of generating such modules is to provide building blocks. Planning alternatives can be easily created with these blocks. The modules can be arranged as needed with their specific cost data. Based on the arranged modules, the planning alternative can be evaluated economically. As a result, this flexible approach helps with generating several system planning alternatives in order to compare them in matters of the costs of NA. The costs of possible NA can therefore be estimated quickly. This evaluation parameter gives hints about the economic extent of costs in the case of NA and is therefore an essential factor in investment decisions. An example of a cost data sheet for modules is shown in Table 1.

Table 1. Example of a cost data sheet for modules (e.g. pallet conveyor with chain and roll, as well as stacker cranes in the high-bay warehouse).

\begin{tabular}{|c|c|c|c|}
\hline \multirow{2}{*}{ 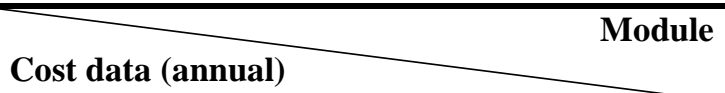 } & \multicolumn{2}{|c|}{ Pallet conveyor } & \multirow{2}{*}{ HBW SC } \\
\hline & chain & roll & \\
\hline \multicolumn{4}{|l|}{ MTBF [h] } \\
\hline \multicolumn{4}{|l|}{ MDT [h] } \\
\hline \multicolumn{4}{|l|}{ Availability $\eta[\%]$} \\
\hline \multicolumn{4}{|l|}{ Costs per unplanned maintenance [€] } \\
\hline \multicolumn{4}{|l|}{ Costs per inspection $[€]$} \\
\hline \multicolumn{4}{|l|}{ Frequency of inspection per year [1/year] } \\
\hline \multicolumn{4}{|l|}{ Width of the module [m] } \\
\hline \multicolumn{4}{|l|}{ Procurement costs per metre [€/m] } \\
\hline \multicolumn{4}{|l|}{ Procurement costs of the module [€] } \\
\hline \multicolumn{4}{|l|}{ Life-time [years] } \\
\hline \multicolumn{4}{|l|}{ Procurement costs of the module per year [€/a] } \\
\hline \multicolumn{4}{|l|}{ Energy consumption (standby) per metre $[\mathrm{kWh} / \mathrm{m}]$} \\
\hline \multicolumn{4}{|l|}{ Energy consumption of the module [kWh] } \\
\hline \multicolumn{4}{|l|}{ Energy price $[€ / \mathrm{kWh}]$} \\
\hline \multicolumn{4}{|l|}{ Energy costs of the module [€] } \\
\hline \multicolumn{4}{|l|}{ Required surface $\left[\mathrm{m}^{2}\right]$} \\
\hline \multicolumn{4}{|l|}{ Surface cost rate $\left[€ / \mathrm{m}^{2}\right]$} \\
\hline \multicolumn{4}{|l|}{ Surface costs of the module $[€]$} \\
\hline \multicolumn{4}{|l|}{ Insurance costs per metre $[€ / \mathrm{m}]$} \\
\hline \multicolumn{4}{|l|}{ Insurance costs of the module [€] } \\
\hline \multicolumn{4}{|l|}{ Length of the module [m] } \\
\hline \multicolumn{4}{|l|}{ Personnel hourly cost rate $[€ / \mathrm{h}]$} \\
\hline Number of employees [number] & & & \\
\hline
\end{tabular}

\subsection{Calculation of the Costs of Non-Availability in a Planning Case}

With the help of an exemplary planning case, the calculation model of the costs of $\mathrm{NA}$ as an evaluation parameter concerning two system alternatives, A and B, is demonstrated. The generated model (see formula (9)) and the module concept (section 7.2) are used for this. 
In the planning case of an $\mathrm{HBW}$, there are two possible alternatives (see Fig. 3). In system A, via chain conveyor (CC A) pallets are transported to roll conveyor (RC A). The RC distributes the pallets on three aisles of an HBW, which are served by the SC A1, A2 and A3 operating parallel. The transfer devices between RC and SC are not considered. In system B, the transport of pallets is also carried on a chain conveyor CC B.

Compared to A, the racks comprise four aisles with four SC. With the help of the calculation approach of formula (9), it should be investigated if an additional aisle in the rack system is cost-effective as regards a possible NA. The two system alternatives therefore have to be compared economically with regard to the costs of NA, and the costs of NA $C_{N A_{(A)}}$ and $C_{N A_{(B)}}$ have to be determined.

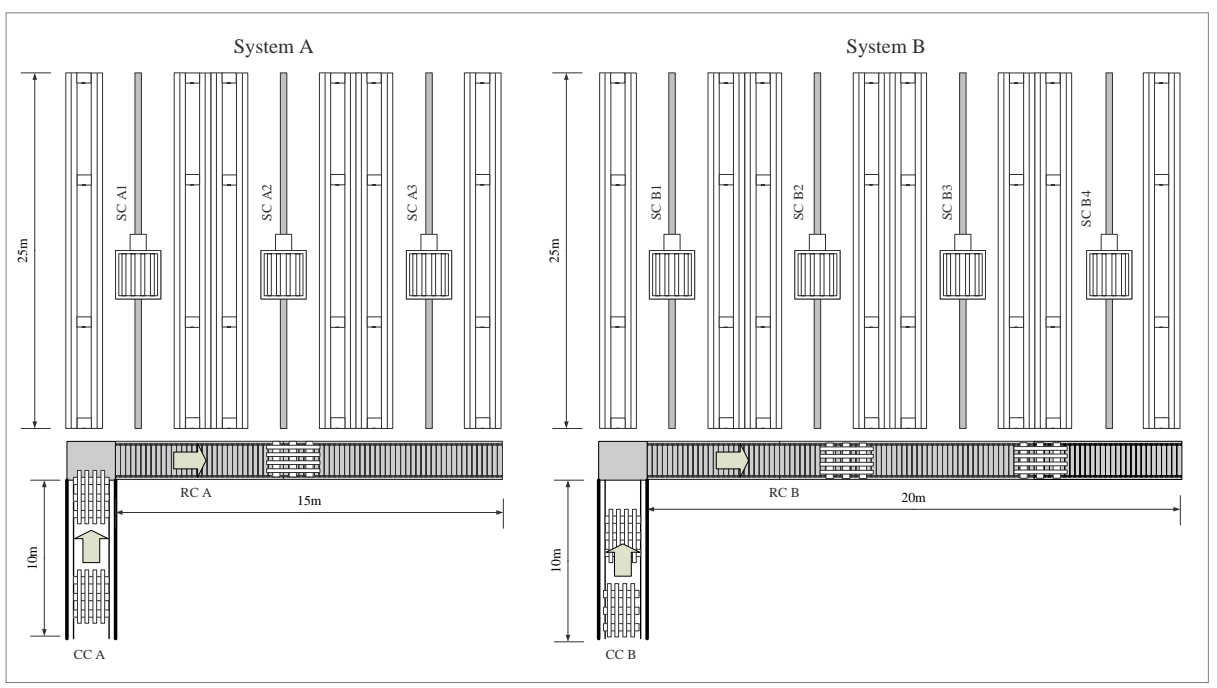

Fig. 3. Schematic representation of system alternatives, $A$ and $B$ : $A$ and $B$ differ with an additional aisle in system $B$.

The availability of system A is given as $99.702209 \%$ and as $99.702222 \%$ of system B which proves to be less of a difference. The specific availability of A and B was determined with the help of the single availabilities of modules and the Boolean notation [19].

The calculation of the costs of NA follows the approach of formula (9). The inspection costs of each module include the costs of planned maintenance and are given as a lump sum, which is multiplied by the number of inspections per year in respect of the planned maintenance works. The number of repairs is the ratio of operating period $T_{B}$ to $M T B F$ which is multiplied by the cost rates for repairs. The cost rates for energy, surface, space, personnel and insurance are then added. The OC are implemented

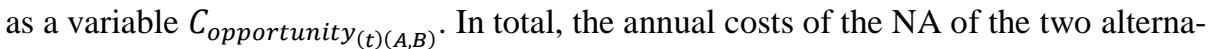
tives are: 


$$
\begin{aligned}
& \mathrm{C}_{\mathrm{NA}_{(\mathrm{A})}}=701,198.08 €+\mathrm{C}_{\text {opportunity }(\mathrm{t})(\mathrm{A})} \text { for system A and } \\
& C_{N A_{(B)}}=848,792.17 €+C_{\text {opportunity }_{(t)(B)}} \text { for system B. }
\end{aligned}
$$

The realisation of alternative B with an improved availability can be justified if

$$
\begin{aligned}
& C_{N A_{(B)}} \leq C_{N A_{(A)}} \\
& C_{\text {opportunity }(t)(A)}-C_{\text {opportunity }(t)(B)} \geq 147,594.09 €
\end{aligned}
$$

The results show that the implementation of an additional aisle with one SC causes a minimal improvement of the total availability. If the difference of the OC of A and B is higher than the difference of the NA-dependent LCC, the realisation of B can be justified even in the case of a higher investment for B. The OC of B can be assumed smaller than that of A because of the improved throughput and capacity so that losses of revenues or penalties should be compensated.

As a result, it has to be investigated whether the lower costs of NA towards a higher availability of the system is an adequate option regards the OC. Higher storage and retrieval performance enabled by the additional SC can generate higher revenues which may reduce OC and therefore the costs of NA.

As regards this planning example, the implementation of an additional aisle can be justified in respect of the requirements of formula (14).

\subsection{Discussion of the Results and Evaluation of the Model}

The database, which is used to determine the module cost data, is extensive, but not all the required input variables can be derived from it. In addition, assumptions are made, which should be examined in detail and confirmed. This includes the assumption of considering AO as surface costs. The space costs are not considered due to lack of data. The database also refers to a specific project and to a comparatively short period. In particular, data for maintenance and repair should be generated and analysed over longer periods, ideally over the entire life-cycle. Furthermore, the calculation of the OC is decisive - this does, however, comprise several problems and challenges because a standardised approach for its calculation does not exist.

By increasing the database, further modules, such as conversion devices and sequencers, as well as other conveyor system modules and SC, can be integrated into the module kit. For example, a corporate database of modules with cost data sheets based on the actual costs thus enables an approach for modelling more complex system planning alternatives. Nevertheless, this approach does provide a quick, loweffort way to evaluate systems with regard to their availability and cost-effectiveness in relation to a possible NA.

With the help of the model, NA can be recorded and evaluated in monetary units. The consideration and reduction of these costs are necessary, especially against the background of competitiveness. Intralogistics costs are therefore not only operating costs, but also the costs of non-operation with their financial consequences, which should be considered in terms of a larger logistical framework. When comparing 
planning alternatives, conclusions can be made as to whether an intralogistics system is cost-effective, also in the case of NA. Furthermore, it can be investigated whether additional modules, like the additional aisle in the planning example, are economically worthwhile.

\section{Summary and Outlook}

The aim of this paper was to develop a model for calculating the costs of the NA of intralogistics systems. The procedure of model generation, a definition of the costs of NA, the state-of-the-art and the system boundary were presented. In the state-of-theart, the various concepts for the costs of NA were defined in order to clearly distinguish the subject matter. Existing models for the costs of NA and maintenance cost calculation were described. The existing maintenance cost models were used as a basis for the generation of the NA cost model.

Then, a holistic calculation model for the costs of NA as a monetarisation approach was developed. This calculation model allows the generation of an evaluation parameter in addition to the criterion of LCC, in order to select and compare system planning alternatives. The model comprises costs which are caused by NA, or which are generated during the NA, with their consequential costs.

The model's application, as well as the data acquisition, have been demonstrated with the help of a planning example. The modules and module cost data sheet generation were discussed in detail. Based on the exemplary module kit, system alternatives were able to be mapped. In the example, the costs of NA were calculated for two planning alternatives and evaluated.

In a critical analysis of the results, the potential of the approach can be identified. By extending and validating the database, it is possible to introduce additional modules of intralogistics systems. Furthermore, a standardised approach for calculating the OC has to be generated. For validation, the use of sensitivity analysis is recommended. The costs of NA should be used as an additional criterion to the LCC within the assessment of planning alternatives aiming at investment decision making in terms of a larger logistical framework.

Acknowledgments. The authors are grateful for the support of the Dr. Friedrich Jungheinrich Foundation. Any opinions, findings, conclusions or recommendations expressed in this paper are those of the writers.

\section{References}

1. Weber, J.: Logistikkostenrechnung: Kosten-, Leistungs- und Erlösinformationen zur erfolgsorientierten Steuerung der Logistik. Springer Vieweg, Berlin/Heidelberg (2012)

2. Doha, A., Das, A., Pagell, M.: The Influence of Product Life Cycle on the Efficacy of Purchasing Practices. International Journal of Operation \& Production Management 33 (4), 470--498 (2013)

3. Gudehus, T.: Logistik: Grundlagen - Strategien - Anwendungen. Springer, Berlin (2010) 
4. Verein Deutscher Ingenieure: Availability of Transport and Storage Systems including Subsystems and Elements (VDI 3581). Beuth, Berlin (2004)

5. Deutsches Institut für Normung e.V.: Dependability Management: Part 3-3: Application Guide: Life Cycle Costing (DIN 60300-3-3). Beuth, Berlin (2005)

6. Deutsches Institut für Normung e.V.: Steel Static Storage Systems: Application and Maintenance of Storage Equipment (DIN 15635). Beuth, Berlin (2009)

7. Dhillon, B.: Life Cycle Costing for Engineers. CRC Press, Boca Raton (2010)

8. Fürnrohr, M.: Stochastische Modelle zur Prognose von Lebenszykluskosten komplexer Modelle: Dissertation. Universität der Bundeswehr, München (1992)

9. Ostwald, P., McLaren, T.: Cost Analysis and Estimating for Engineering and Management. Pearson Prentice Hall, New Jersey (2004)

10. Fritz, A.: Berechnung und Monte-Carlo Simulation der Zuverlässigkeit und Verfügbarkeit technischer Systeme: Dissertation. Universität Stuttgart, Stuttgart (2001)

11. Fleischer, J., Wawerla, M., Niggeschmidt, S.: Machine Life Cycle Cost Estimation via Monte-Carlo Simulation. In: Takata, S., Umeda, Y. (eds.) Advances in Life Cycle Engineering for Sustainable Manufacturing Businesses: Proceedings of the 14th CIRP Conference on Life Cycle Engineering, pp. 449--453. Springer, London (2007)

12. Elsayed, E.: Reliability Engineering. Wiley, New Jersey (2012)

13. Lad, B., Kulkani, M.: Integrated Reliability and Optimal Maintenance Schedule Design: A Life Cycle Based Approach. International Journal of Product Lifecylce Management 3, 78-90 (2008)

14. Verband Deutscher Maschinen- und Anlagenbau e. V.: Forecasting Model for Lifecycle Costs of Machines and Plants (VDMA 34160). Beuth, Berlin (2006)

15. Dervisopoulos, M., Schatka, A., Torney, M.: Life Cycle Costing im Maschinen- und Anlagenbau. Industrie Management 22, 55--58 (2006)

16. Höck, M.: Dienstleistungsmanagement aus produktionswirtschaftlicher Sicht. Betriebswirtschaftliche Forschung zur Unternehmensführung. Deutscher Universitätsverlag, Wiesbaden (2005)

17. Günthner, W.A., Habenicht, S.: Erweiterte Logistikplanung unter Einbeziehung des Energieverbrauchs: Forschungsbericht der AiF-Forschungsvereinigung Bundesvereinigung Logistik e. V. (BVL). Berlin (2013)

18. Günthner, W.A., Habenicht, S., Ertl, R.: Analytische Energiebedarfsermittlung von Intralogistiksystemen in der Planungsphase: Tagungsband WGTL-Kolloquium, 77--90. Garching (2013)

19. Verein Deutscher Ingenieure: Boolean Model (VDI 4008). Beuth, Berlin (1998) 